\title{
PENGARUH KOMBINASI PIJAT ENDORPHIN DAN MURROTAL TERHADAP NYERI PERSALINAN KALA I DI PMB NY. N PASPAN KABUPATEN BANYUWANGI
}

\section{The Effect of Giving a Combination of Endorphin and Murotal Massage On Labor Pain In The Phase I}

\section{Indah Christiana, Diana Kusumawati}

\author{
Sekolah Tinggi Ilmu Kesehatan Banyuwangi
}

\section{Riwayat artikel}

Diajukan: 19 Agustus 2021

Diterima: 16 September 2021

\section{Penulis Korespondensi:}

- Indah Christiana

- Sekolah Tinggi Ilmu

Kesehatan Banyuwangi e-mail:

indahchristiana@stikesb

anyuwangi.ac.id

\section{Kata Kunci:}

endorphin murrotal, labor pain

\begin{abstract}
Abstrak
Pendahuluan : Pada saat proses persalinan terjadi kontraksi uterus, dilatasi serviks dan peregangan segmen bawah uterus yang menyebabkan rasa nyeri. Nyeri selama persalinan yang tidak teratasi dengan baik dapat mempengaruhi mekanisme fisiologis sejumlah sistem tubuh. Nyeri persalinan selain dapat diatasi dengan pijat endorphin, juga dapat diatasi dengan terapi murottalt. Tujuan meneliti pengaruh terapi pijat endorphin dan Murrotal terhadap nyeri persalinan kala I di PMB Ny. N Paspan Kabupaten Banyuwangi. Metode: Desain penelitian ini menggunakan Quasy Eksperimental dengan pre-test - post test control group. Populasi pada penelitian ini sejumlah 21 ibu bersalin dengan jumlah sampel sebanyak $20 \mathrm{ibu}$ bersalin, yang dibagi menjadi $10 \mathrm{ibu}$ bersalin pada kelompok perlakuan dan $10 \mathrm{ibu}$ bersalin pada kelompok kontrol dengan menggunakan teknik accidental sampling. Alat ukur yang digunakan adalah kuesioner dan lembar observasi, data yang terkumpul kemudian diuji denganWilcoxon Signed Rank. Hasil: setelah dilakukan uji statistik Wilcoxon Signed Rank Test diperoleh Asimp.sig (2-tailed) 0,004 < $\alpha(0,05)$,dimana terdapat perbedaan sebelum dan sesudah diberikan pijat endorphin dan Murrotal, maka bisa diartikan hasilnya terdapat pengaruh pijat endorphin dan murrotal pada nyeri persalinan kala I Kesimpulan: terdapat pengaruh pijat endorphin dan murrotal pada nyeri persalinan kala I.
\end{abstract}

\section{Abstract}

Background: During labor, uterine contractions, cervical dilatation and stretching of the lower uterine segment cause pain.Pain during labor that is not resolved properly can affect the physiological mechanisms of a number of body systems. In addition to labor pain can be overcome with endorphin massage, can also be overcome with murottal therapy. The purpose of this To examine the effect of endorphin and Murrotal massage therapy on labor pain in the first stage at PMB Miss. N Paspan Banyuwangi Regency. Method: The design of this study used Quasy Experimental with pre-test-post testcontrol group. The population in this study were 21 mothers who gave birth with a sample of 20 mothers who gave birth were divided into 10 women who gave birth in the treatment group and 10 women who gave birth in the control group by using accidental sampling technique. The measuring tools used are questionnaires and observation sheets, the data collected is then tested with the Wilcoxon Signed Rank. Results: There is an effect of a combination of endorphin and Murrotal massage on labor pain in the first stage with a significant degree of $<0.05$. Conclusion: The implication of this study is to reduce labor pain in the first stage of labor by using a combination ofendorphin and murrotal massage 


\section{PENDAHULUAN}

Persalinan merupakan proses keluarnya hasil konsepsi (janin, plasenta dan cairan ketuban), baik cukup bulan maupun kurang bulan, baik melalui jalan lahir maupun jalan yang lain yang ditandai dengan membuka dan menipisnya serviks(Manuaba, 2012). Pada saat proses persalinan terjadi kontraksi uterus, pembukaan serviks dan peregangan segmen bawah uterus yang menyebabkan rasa nyeri (Maryunani, 2010). Nyeri persalinan merupakan kondisi yang normal dalam proses persalinan dimana dapat timbul rasa tidak nyaman yang disebabkan karena rangsangan ujung saraf tertentu (Alyensi \& Arifin, 2017).

Di Amerika Serikat 70\% - 80\% wanita yang melahirkan mengharapkan persalinan tidak menimbulkan rasa sakit. Saat ini, 20\% sampai 50\% ibu yang mau bersalin di rumah sakit di negara berkembang lebih memilih melakukan operasi caesar karena dianggap relatif tidak menimbulkan rasa sakit, (Hindriati, dkk., 2019). Mulyani (2018) menyatakan di Indonesia berdasarkan data perhimpunan Rumah Sakit Indonesia menemukan bahwa $15 \%$ ibu melahirkan mengalami komplikasi persalinan, $21 \%$ ibu bersalin mengatakanpersalinannya menyakitkan, sedangkan $63 \%$ ibu tidak mengetahui persiapan yang diperlukan untuk mengurangi nyeri persalinan. Data RISKESDAS tahun 2018 di Jawa Timur terdapat $76,9 \%$ dari ibu bersalin melakukan persalinan dengan persalinan normal (Kemenkes, 2018). Di Banyuwangi pada tahun 2017 yaitu dari 23.003 ibu bersalin terdapat $19.595 \mathrm{ibu}$ dengan persalinan normal (Dinas Kesehatan Kabupaten Banyuwangi, 2017).

$$
\text { Nyeri pada kala I }
$$
persalinandisebabkan oleh kontraksi rahim yang menyebabkan otot-otot dinding rahim Prevalensi gangguan jiwa wilayah berkontraksi, menekan pembuluh darah danmerelaksasi vagina dan jaringan lunak sekitarnya (Maryunani, 2010). Nyeri selama persalinan yang tidak teratasi dengan baik akan menganggu mekanisme fisiologis sistem tubuh. Pada sistem pernafasan, nyeri persalinan kala I dapat menyebabkan hiperventilasi pada ibu bersalin sehingga teradi penurunan kadar $\mathrm{PaCO} 2$ dalam tubuh. Jika kadar $\mathrm{PaCO} 2$ pada ibu mengalami penurunan maka kadar $\mathrm{PaCO} 2$ janin juga mengalami penurunan, hal ini dapat menyebabkan deselarasi lambat denyut jantung janin. sedangkan pada sistem kardiovaskuler nyeri persalinan yang tidak teratasi dapat meningkatkan curah jantung, penigkatan tekanan darah dan dapat mempengaruhi hormon adrenalin dan kortisol, menyebabkan penurunan aktivitas rahim, dan menyebabkan komplikasi pada persalinan dan dapat menjadi salah satu penyebab kematian baik pada ibu maupun anak (Hasnah, 2018). Selain itu nyeri persalinan juga dapat mempengaruhi psikologis ibu. Nyeri yang tidak diobati menyebabkan rasa cemas pada ibu, dan sebaliknya rasa cemas berlebihan juga dapat menambah intensitas nyeri yang dirasakan ibu bersalin(Maryunani, 2010).

Penatalaksanaan nyeri persalinan dapat dilakukan dengan cara farmakologi dan non-farmakologi (Maryunani, 2010) Terapi non-farmakologi untuk menangani nyeri persalinan diantaranya hypnobirthing, akupuntur, akupresur, water birth, massage (pijat) (Maryunani, 2010). Massage (pijat) yang dapat diberikan kepada ibu hamil salah satunya dengan pijat endorphin (Irawati, 2018). Pijat endorphinini adalah metode sentuhan lembut yang digunakan pada wanita untuk menghilangkan rasa sakit saat melahirkan dan untukmeningkatkan relaksasi dengan menciptakan perasaan nyaman pada permukaan kulit. Hal ini karena pijat merangsang tubuh untuk merangsang endorphin yang menghilangkan rasa sakit dan dapat mencipkana perasaan nyaman (Aprilia, 2010). 
Nyeri persalinan dapat diatasi tidak hanya dengan pijatan endorphin, tetapi juga dengan terapi murottal (Trianingsih, 2019). Terapi murottal merupakan salah satu jenis audioanalgesia yang dapat diberikan kepada ibu bersalin (Alyensi \& Arifin, 2017). Terapi murottal dipercaya dapat menenangkan fisik dan psikis melalui aspek spiritual sehingga dapat menurunkan intensitas nyeri persalinan (Diana, 2016). Terapi Al Quran telah terbukti mengaktifkan sel-sel tubuh dengan mengubah getaran suara menjadi gelombang yang diterima tubuh, mengurangi reseptor rasa sakit dan menyebabkan otak melepaskan opioid alami endogen.Opioid ini bersifat permanen untuk memblokir noniceptor nyeri (Rilla, dkk., 2014). Terapi murottal mampu merelaksasi ibu sehingga tubuh mengeluarkan endorphin yang dapat menghambat pelepasan substansi P (substancia gelatinosa) di kornu dorsalis di medula spinalis sehingga tidak terjadi sensasi nyeripada korteks cerebri. Hormon endorphin yang dikeluarkan oleh tubuh juga dapat berupa neurotransmitter atau neuromedulator yang menghambat transmisi nyeri, sehingga ibu bersalin akan merasa lebih tenang (Alyensi \& Arifin, 2017).

Melihat pentingnya pemberian terapi terhadap nyeri persalinan kala I, maka perlu diberikan inovasi dalam penanganan nyeri persalinan kala I dengan terapi kombinasi pijat endorphin dengan audiotori murottal. Prinsip dalam terapi yang digunakan peneliti yaitu, menggabungkan terapi dari aspek fisik, psikis dan spiritual

\section{METODE}

Desain penelitian ini menggunakanQuasy Eksperimental dengan metode pre-test - post test control group. Populasi dalam penelitian ini berjumlah 21 orang dengan jumlah sampel 20 orang ibu bersalin, terbagi menjadi 10 ibu bersalin pada kelompok intervensi dan $10 \mathrm{ibu}$ bersalin pada kelompok kontrol yang memenuhi kriteria inklusi : ibu bersalin dalam kala I, koorperatif dan beragama islam, kriteria eksklusi ibu hamil datang dengan pembukaan lengkap. Tehnik sampling yang gunakan adalah teknik accidental sampling. ibu bersalin pada kelompok intervensi diberikan tindakan pijat endorphin bersamaan dengan pemberian murotal surat arrohman selama 15 menit. Kuesioener dan lembar observasi digunakan sebagai alat ukur. Analisis data denganWilcoxon Signed Rank

\section{HASIL DAN PEMBAHASAN}

\section{HASIL}

\section{Karakteristik Berdasarkan Usia}

Tabel 1 Karakteristik responden berdasarkan usia pada kelompok intervensi dan kontrol di PMB Ny. N Paspan Banyuwangi ( $\mathrm{n}=20 \mathrm{ibu}$ bersalin)

\begin{tabular}{lcccl}
\hline $\begin{array}{l}\text { Usia } \\
\text { (dalam } \\
\text { tahun) }\end{array}$ & $\begin{array}{c}\text { Kelompok } \\
\text { Intervensi }\end{array}$ & $\begin{array}{c}\text { Kelompok } \\
\text { Kontrol }\end{array}$ \\
\cline { 2 - 5 } & Jumlah & $\%$ & Jumlah & $\%$ \\
\hline$<20$ & 1 & 10 & 0 & 0 \\
$20-35$ & 7 & 70 & 9 & 90 \\
$>35$ & 2 & 20 & 1 & 10 \\
\hline Total & 10 & 100 & 10 & 100 \\
\hline
\end{tabular}

Dari tabel 1 diatas dapat disimpulkan bahwa pada kelompok intervensi sebagian besar 7 responden $(70 \%)$ berusia antara 20 35 tahun, sedangkan pada kelompok kontro hampir seluruhnya 9 responden (90\%) berusia antara 20-35 tahun

\section{Karakteristik}

\section{Berdasarkan Paritas}

Tabel 2 Karakteristik responden berdasarkan paritas pada kelompok intervensi dan kontrol di PMB Ny. N Paspan Banyuwangi ( $\mathrm{n}=20 \mathrm{ibu}$ bersalin).

\begin{tabular}{lcccc}
\hline Paritas & \multicolumn{2}{c}{$\begin{array}{c}\text { Kelompok } \\
\text { Intervensi }\end{array}$} & \multicolumn{2}{c}{$\begin{array}{c}\text { Kelompok } \\
\text { Kontrol }\end{array}$} \\
\cline { 2 - 5 } & Jumlah & $\%$ & Jumlah & $\%$ \\
\hline Primigravida & 5 & 50 & 5 & 50 \\
\hline
\end{tabular}




\begin{tabular}{lllll}
\hline Multigravida & 5 & 50 & 5 & 50 \\
Grandemulti & 0 & 0 & 0 & 0 \\
\hline Total & 10 & 100 & 10 & 100 \\
\hline
\end{tabular}

Dari tabel 2 diatas dapat disimpulkan bahwa pada kelompok intervensi dan kontrol separuhnya 5 responden $(50 \%)$ adalah primigravida (hamil yang pertama kali) dan separuhnya lagi 5 responden $(50 \%)$ adalah multigravida (hamil lebih dari 1 kali).

3. Karakteristik

\section{Berdasarkan Pendidikan}

Tabel 3 Karakteristik responden berdasarkan pendidikan pada kelompok intervensi dan kontrol di PMB Ny. N Paspan Banyuwangi ( $\mathrm{n}=20 \mathrm{ibu}$ bersalin)

\begin{tabular}{lcccc}
\hline Pendidikan & \multicolumn{2}{c}{$\begin{array}{c}\text { Kelompok } \\
\text { Intervensi }\end{array}$} & \multicolumn{2}{c}{$\begin{array}{c}\text { Kelompok } \\
\text { Kontrol }\end{array}$} \\
\cline { 2 - 5 } & Jumlah & $\%$ & Jumlah & $\%$ \\
\hline Rendah & 2 & 20 & 5 & 50 \\
Menengah & 6 & 60 & 5 & 50 \\
Tinggi & 2 & 20 & 0 & 0 \\
\hline Total & 10 & 100 & 10 & 100 \\
\hline
\end{tabular}

Dari tabel 3 diatas dapat disimpulkan bahwa pada kelompok intervensi sebagian

besar 6 responden $(60 \%)$ berpendidikan menengah (SMP-SMA), sedangkan pada kelompok kontrol separuhnya 5 responden (50\%) berpendidikan menengah (SMP-SMA).

\section{Karakteristik}

\section{Berdasarkan Pekerjaan}

Tabel 4 Karakteristik responden berdasarkan pekerjaan pada kelompok intervensi dan kontrol di PMB Ny. N Paspan Banyuwangi ( $\mathrm{n}=20 \mathrm{ibu}$ bersalin)

\begin{tabular}{lcccc}
\hline Pekerjaan & \multicolumn{2}{c}{$\begin{array}{c}\text { Kelompok } \\
\text { Intervensi }\end{array}$} & \multicolumn{2}{c}{$\begin{array}{c}\text { Kelompok } \\
\text { Kontrol }\end{array}$} \\
\cline { 2 - 5 } & Jumlah & $\%$ & Jumlah & $\%$ \\
\hline Tidak & 7 & 70 & 8 & 80 \\
bekerja & & & & \\
Buruh & 0 & 0 & 1 & 10 \\
K. Swasta & 0 & 0 & 1 & 10 \\
Guru & 1 & 10 & 0 & 0 \\
SPG & 1 & 10 & 0 & 0 \\
Bidan & 1 & 10 & 0 & 0 \\
\hline Total & 10 & 100 & 10 & 100 \\
\hline \multicolumn{4}{c}{ Dari tabel 4 diatas dapat disimpulkan } \\
bahwa pada kelompok intervensi sebagian
\end{tabular}

besar 7 responden $(70 \%)$ dan pada kelompok kontrol hampir seluruhnya 8 responden $(80 \%)$ tidak bekerja (IRT).

\section{Hasil Data Khusus}

Pengaruh Pijat Endorphin dan Murrotal terhadap nyeri persalinan kala I Fase Laten

\section{Test Statistics $^{a}$}

\begin{tabular}{lc} 
& setelah \\
& intervensi \\
pijat \\
endorphin \\
dan murotal - \\
sebelum \\
intervensi \\
pijat \\
\\
endorphin \\
& dan murotal \\
\hline Z & $-2.889^{\mathrm{b}}$ \\
\hline Asymp. Sig. (2-tailed) & .004 \\
\hline a. Wilcoxon Signed Ranks Test \\
b. Based on positive ranks.
\end{tabular}

Berdasarkan uji statistik Wilcoxon Signed Rank Test diperoleh Asimp.sig (2-tailed) $0,004<\alpha(0,05)$, dimana terdapat perbedaan sebelum dan sesudah diberikan pijat endorphin dan Murrotal, maka bisa diartikan hasilnya terdapat pengaruh pijat endorphin dan murrotal pada nyeri persalinan kala I.

\section{PEMBAHASAN}

\section{Karakteristik Responden.}

Responden dalam penelitian ini adalah ibu bersalin kala I di PMB Ny. N karakteristik responden yang diteliti yaitu : usia, pendidikan, pekerjaan dan paritas. Dari hasil penelitian hampir seluruhnya responden 16 responden (80\%) berusia diantara 20-35 tahun. Faktor usia memiliki peran penting dalam persalinan, usia yang aman secara fisik maupun psikologis yakni usia diantara 20-35 tahun. Bila ibu bersalin diusia < 20 tahun atau > 35 tahun ibu memiliki resiko tinggi dalam proses 
persalinan. Pada penelitian ini responden memiliki usia yang aman dalam persalinan yakni 20-35 tahun, dimana dengan usia 2035 tahun organ reproduksi sudah matang atau berfungsi dengan baik sehingga aman dalam proses persalinan.

Selanjutnya karakteristik tingkat pendidikan, dari hasil penelitian responden sebagian besar berpendidikan menengah (SMP-SMA) sebanyak 11 reponden (55\%). Tingkat pendidikan berpengaruh pada kemampuan seseorang dalam menerima informasi dan kemampuan mengambil keputusan untuk menjaga kesehatan kehamilannya serta mencari pelayanan kesehatan antenatal yang baik

Karakteristik pekerjaan, sebanyak 15 responden (75\%) adalah ibu rumah tangga (tidak bekerja), responden akan memiliki banyak waktu untuk istirahat dan menjaga kesehatan kehamilannyadibandingkan ibu yang bekerja terlebih pekerjaanya diluar rumah. Karakteristik yang lain adalah paritas, dari hasil penelitian setengah 10 responden $(50 \%)$ kategori primipara. Kontraksi uterus ibu primipara lebih sering dan lebih kuat daripada ibu mutipara.Pada ibu multipara karena sudah memiliki pengalaman dalam proses persalinan akan mudah beradaptasi dengan nyeri kala I dibandingkan ibu primipara yang belum pernah melahirkan.

\section{Pengaruh pemberian kombinasi pijat endorphin dan murotal terhadap nyeri persalinan kala I fase laten}

Seorang wanita yang melahirkan akan merasakan nyeri disebabkan karena adanya kontraksi rahim. Nyeri yang dirasakan setiap individu berbeda-beda, tergantung pada ambang nyeri. Bagi ibu yang belum siap atau belum mempunyai pengalaman persalinan sebelumnya akan dirasakan sebagai pengalaman yang menakutkan (Andarmoyo dan Sukanta 2013).Karena peregangan segmen bawah rahim selama kontraksi serviks, nyeri selama persalinan sebanding dengan kekuatan kontraksi dan tekanan yang dihasilkan. Rasa sakit meningkatsaatserviks benar-benar mengembang mengikuti tekanan bayi pada struktur panggul diikuti robeknyajalan lahir. Intensitas nyeri seseorang dipengaruhi banyak factor seperti: factor kesehatan fisik, psikologis, usia, budaya dan lingkungan.

Dari hasil penelitian ini yang diuji dengan metode statistic wilcoxon diperoleh nilai $\mathrm{p}$ value $0,004<\alpha=0,05$ yang berarti terdapat perbedaan nyeri persalinan pada kelompok perlakuan dengan kelompok control yang tidak diberikan pijat endorphin dan murotal,hasil ini sesuai dengan penelitian yang dilakukan Iin Nurazizah 2011 tentang pengaruh pijat endorphin terhadap intensitas nyeri persalinan kala I. dimana hasilnya menunjukkan adanya pengaruh pijat endorphin terhadap intensitas nyeri persalinan kala I. Sedangkan menurut penelitian Rohmi Handayani dkk, yang berjudul Pengaruh Terapi Murottal AlQur'an Terhadap Penurunan Intensitas Nyeri Persalinan Kala I di RSUD Prof. dr. Margono Soekardjo Tahun 2014 , rerata intensitas nyeri adalah 6,57 sebelum terapi murrotal, dan 4,93 setelah terapi murrotal. Uji Paired T-test menunjukkan perbedaan rerata penurunan intensitas nyeri persalinan kala I sebelum dan sesudah terapi murottal dengan $p$ value $0,000<\alpha=0,05$.

Pijat endorphin memiliki pengaruh fisiologis pada peredaran darah dibagian jaringan otot terdalam, dapat menimbulkan rasa nyaman yang mencegah sensasi rasa sakit yang terjadi saat kontraksi. Pijat endorphin digunakan untuk mekanisme yang melepaskan endorphin, mengontrol saraf dan merangsang saraf simpatik sehingga otot rileks (Apriliya, 2010). Begitu juga dengan pemberian murotal ayat-ayat alquran dapat memberikan pengaruh terhadap perspektif fisiologis dan psikologis yang luar biasa dimana dengan mendengarkan ayat-ayat suci alquran mendatangkan ketenangan dan menurunkan ketegangan urat saraf reflector yang dapat menurunkan nyeri persalinan kala I. 


\section{KESIMPULAN}

Kombinasi pijat endorphin dan murrotal mempengaruhi skala nyeri persalinan kala I di PMB Ny. N Paspan Banyuwangi.

\section{IMPLIKASI}

Bidan dapat menggunakan kombinasi pijat endorphin dan murrotal untuk meredakan nyeri persalinan pada wanita saat melahirkan

\section{DAFTAR PUSTAKA}

Alyensi, F., \& Arifin, H. (2017). Pengaruh Terapi Murottal Qur'an Terhadap Intensitas Nyeri Persalinan Kala I Fase Aktif Di Bidan Praktik Mandiri (BPM) Ernita Kota Pekanbaru Tahun 2017. Jurnal Kebidanan, 8(1), 31-39. Retrieved from https://www.google.com/url?sa=t\&rct $=\mathrm{j} \& \mathrm{q}=\&$ esrc $=\mathrm{s} \&$ source $=$ web $\& \mathrm{~cd}=3 \&$ $\mathrm{cad}=\mathrm{rja} \& u a c t=8 \& v e d=2$ ahUKEwi_4re Tp_31AhUSxTgGHVMSAC0QFjACe gQIBBAC\&url=http $\% 3 \mathrm{~A} \% 2 \mathrm{~F} \% 2 \mathrm{Fejo}$ urnal.poltekkessmg.ac.id\%2Fojs\%2Findex.php\%2Fju rkeb\%2Farticle\%2Fdownload\%2F372 9\%2F911\&usg=AOvVaw3YTCJVEY $\mathrm{U}$

Andarmoyo, S. (2013). Persalinan Tanpa Nyeri Berlebihan. Yogyakarta: ArRuzz Media.

Aprilia, Y. (2010). Hipnosentri: Rileks, Nyaman, Dan Aman Saat Melahirkan. Jakarta: Gagas Media.

Diana, U. (2016). Gambaran Pemberian Auditory Murottal terhadap Penurunan Rasa Nyeri Ibu Inpartu Kala I Fase Aktif di Rumah Bersalin Mattiro Baji Kabupaten Gowa Sulawesi Selatan Tahun 2016 (Fakultas Kedokteran Dan Ilmu Kesehatan Universitas Islam Negeri Alauddin Makassar). Retrieved from http://repositori.uin-

alauddin.ac.id/4130/

Dinas Kesehatan Kabupaten Banyuwangi. (2017). Profil Kesehatan Banyuwangi, 7.

Hasnah, H., Kb,M.A.R., \& Muaningsih, M. (2018). Literatur Review : Tinjauan tentang Efektifitas Terapi Non Farmakalogis terhadap Penurunan Intensitas Nyeri Persalinan Kala I. Jurnal Of Islamic Nursing, 3 (2), 45.https://doi.org/10.2452/1join.v3i2.6 854

Hindriati, T., Novilda, A., Bidan, M., \& Rafida, N. (2019). Pengaruh Effleurage Massage terhadap Nyeri Persalinan Kala I Fase Aktif di Praktik Mandiri Bidan Nuriman Rafida dan Praktik Mandiri Bidan Latifah Kota Jambi Tahun 2019. 19(3), 590-601. https://doi.org/10.33087/jiubj.v19i3.76 4

Maryunani, A. (2010). Nyeri Dalam Persalinan Teknik dan Cara Penanganan. Jakarta: CV. Trans Info Media.

Mulyani, A. (2018). Pengaruh Aplikasi Kontraksi Nyaman Terhadap Perubahan Intensitas Nyeri Pada Persalinan Kala 1 Fase Aktif Di Wilayah Kerja Puskesmas Cibeureum Kota Tasikmalaya Tahun 2017. Jurnal Kesehatan Bakti Tunas Husada: Jurnal Ilmu-Ilmu Keperawatan, Analis Kesehatan Dan Farmasi, 17(2), 202. https://doi.org/10.36465/jkbth.v17i2.2 23

Rilla, E. V., Ropii, H., \& Sriati, A. (2014). Terapi Murottal Efektif Menurunkan Tingkat Nyeri Dibanding Terapi Musik pada Pasien Pascabedah.Jurnal Keperawatan Indonesia, 17(2), 74-80. https://doi.org/10.7454/jki.v17i2.444 
Trianingsih, I. (2019). Pengaruh Murotal Al

Qur'an dan Dzikir Terhadap Intensitas

Nyeri Kala I Persalinan. 15(1), 26-30. 